\title{
A sensitive semi-quantitative analysis of patent blue $v$ in drinks with SERS
}

\author{
S. Chen ${ }^{1,2}$, K.-H. Ouyang ${ }^{1}$, R.-M. Wu ${ }^{3}$, P. Guo ${ }^{4}$, W.-J. Wang ${ }^{1,2^{*}}$ and D. Wang ${ }^{4 *}$ \\ ${ }^{1}$ Jiangxi Province Key Laboratory of Animal Nutrition/Engineering Research Center of Feed Development, Jiangxi Agricultural \\ University, Nanchang 330045, China P.R.; ${ }^{2}$ College of Food Science and Engineering, Jiangxi Agricultural University, Nanchang \\ 330045, China P.R.; ${ }^{3}$ Optics-Electrics Application of Biomaterials Lab, Jiangxi Agricultural University, Nanchang 330045, \\ China P.R.; ${ }^{4}$ Jiangxi Institute for Food Control, Nanchang 330038, China P.R.; wwjun9999@sina.com; hovyfan@qq.com
}

Received: 7 May 2019 / Accepted: 18 November 2019

(c) 2019 Wageningen Academic Publishers

OPEN ACCESS CC) RE(-) REARCH ARTICLE

\begin{abstract}
Patent blue v, one of synthetic colours, is commonly used to improve the appearance of foods in Europe, but the health concerns associated with synthetic colours has been sometimes reported. In present study, a sensitive and simple analytical method for patent blue $v$ in drinks was established by surface enhanced Raman scattering (SERS). Two gold nanoparticles synthetic methods were compared and the characteristic peaks for patent blue v were certified by density functional theory. The results showed that the intensity of $1,182 \mathrm{~cm}^{-1}$ semi-quantitative peak was proportional to the concentration of patent blue $\mathrm{v}$. The detection limit concentrations were among 0.5 to 1.0 $\mathrm{mg} / \mathrm{kg}$ in different drinks. The relative standard deviations were below $7.75 \%$, and the average recovery rate was in the range from $92.09 \%$ to $104.55 \%$. In conclusion, the application of SERS method has a promising prospect in drinks to detect patent blue $\mathrm{v}$ because of its simplicity and efficiency.
\end{abstract}

Keywords: patent blue v, analytical methods, biotechnology, contaminants, crops

\section{Introduction}

Synthetic colours, with characteristics of appealing colour and good stability, are extensively utilised in foods to prolong the shelf life, and to improve appearance and storage quality of the final products (Peksa et al., 2015). Despite the lack of enough evidence to prove their harm on human beings, there are a lot of health concerns associated with synthetic colours in United Kingdoms and other countries all over the world (Gukowsky et al., 2018; Lofstedt, 2011). Patent blue $v\left(\mathrm{C}_{27} \mathrm{H}_{32} \mathrm{~N}_{2} \mathrm{O}_{7} \mathrm{~S}_{2} \cdot 1 / 2 \mathrm{Ca}\right)$ is categorised into triarylmethane colours, and is largely used in drinks, pastries, protein products, cheese and other food products (Ai et al., 2018). According to the European Food Safety Authority, the acceptable daily intake of patent blue $v$ is 5 $\mathrm{mg} / \mathrm{kg}$ bw/day for all groups of population in EU (EFSA, 2013). But it has been forbidden to add into foods in China. In 2014, a batch of imported confectioneries were destroyed by Shanghai Pudong Inspection and Quarantine Bureau because of the presence of patent blue $v$. The conventional detection methods for synthetic colours include enzymelinked immunosorbent assay (Oplatowska et al., 2011), high performance liquid chromatography (Xian et al., 2013), liquid chromatography-mass spectrometry (Genualdi $e t$ al., 2016), electrochemical method (Gao et al., 2014) and so on. However, these methods usually are sophisticated to operate, high costs and need a large number of organic solvents, making them not suitable for real-time detection.

Raman spectra are designed to observe the scattering phenomenon caused by the change of the frequency of incident light generated by the interaction of electromagnetic radiation with matter. With the invention of strong tunable lasers and development of nanostructured metal, the Raman spectroscopy is regarded as a sensitive and rapid analytical technique to probe structural details of samples because of the correlations between the frequency and the chemical structure (Benedetti et al., 2014; Li et al., 2013; Sur, 2017). Considering that the Raman scattering intensity is extremely weak, the surface enhanced Raman scattering (SERS) is invented to increase the signal intensity of analytes absorbed on the rough surface of nanoparticles (about 106-14) (Haruka, 1987). Because of many advantages of SERS, including easy to operate, no pretreatment 
requirements, and high sensitivity, it is widely used to analyse toxic and hazardous substances, such as pesticide residue (Cai et al., 2017; Xu et al. 2017; Zhu et al., 2018), drug detection (Aoki et al., 2013; Lee et al., 2016; Siddhanta et al., 2016), environmental monitoring (Zhou et al., 2012), biological detection (Chen et al., 2018; Pearson et al., 2018) and food additives (Han et al., 2017; Ma et al., 2014; Meng et al., 2016; Sharma et al., 2016; Wang et al., 2015, 2018; Xie et al., 2012, 2019;). However, to the best of our knowledge, the detection of patent blue $v$ in drinks by SERS has not yet been reported.

Therefore, the present study established a rapid detection method of patent blue $v$ in three drinks by gold nanoparticles (Au NPs) based SERS technique, which allowed direct detection of patent blue $v$ in liquid food matrices. Moreover, the synthesis methods of Au NPs and electrolyte were investigated.

\section{Materials and methods}

\section{Reagents and samples}

Phytic acid $\left(\mathrm{IP}_{6}\right)$ was purchased from Shanghai Macklin Biochemical Technology Co., Ltd (Shanghai, China). Tetrachloroauric acid trihydrate $\left(\mathrm{HAuCl}_{4} \cdot 4 \mathrm{H}_{2} \mathrm{O}\right)$, sodium chloride $(\mathrm{NaCl})$, magnesium sulphate $\left(\mathrm{MgSO}_{4}\right)$ and tri-sodium citrate dehydrate (TC) were obtained from Sinopharm Chemical Reagent Co., Ltd (Shanghai, China). Patent blue v was provided by the Food and Drug Administration of Jiangxi Province. Gatorade sports drink, blended fruit drink and Rio cocktail without patent blue v were purchased in Wal-Mart (Nanchang, Jiangxi, China). All chemicals and reagents were of analytical grade. Ultrapure water was used throughout the experiment.

\section{Instrument}

Ram Tracer -200-HS (Opto Trace Technologies Co., Ltd., Suzhou, China) equipped with $785 \mathrm{~nm}$ Frequency Stablized Laser was used to collect Raman spectra recorded from $100 \sim 3,300 \mathrm{~cm}^{-1}$. Hitachi S-4800 (the Hitachi Company, Beijing, China) was used to obtain the scanning electron microscope (SEM) image of nanoparticles. UV-visible absorption spectroscopy was the type of T6 (Beijing Puxi General Instrument Co., Ltd, , Beijing, China).

\section{Samples preparation}

Patent blue $\mathrm{v}$ aqueous solution was prepared by dissolving $50 \mathrm{mg}$ of patent blue $\mathrm{v}$ in $100 \mathrm{ml}$ ultrapure water. After ultrasound treatment to remove carbon dioxide, three different samples were prepared by adding $2 \mathrm{ml}$ of patent blue v aqueous solution into Gatorade sports drink, blended fruit drink and Rio cocktail. The prepared samples were diluted with blank drinks to obtain the final concentrations of Gatorade sports drink (11.10, 9.87, 8.48, 5.99, 3.99, 3.0, 2.0, $1.0,0.51 \mathrm{mg} / \mathrm{kg})$, blended fruit drink (11.94, 10.0, $8.95,7.96,5.98,4.99,3.96,2.99,0.99,0.49 \mathrm{mg} / \mathrm{kg}$ ) and Rio cocktail $(7.24,6.35,5.63,4.98,3.58,2.39,1.97,1.30,0.53$, $0.26 \mathrm{mg} / \mathrm{kg})$.

\section{Comparison of different synthetic methods of Au NPs}

To increase Raman spectra intensity, two synthetic methods of Au NPs were investigated. Method 1 was conducted as follows: $100 \mathrm{ml}$ of $0.25 \%$ tetrachloroauric acid trihydrate was added into three neck flasks and then heated to boiling point. $3.7 \mathrm{ml}$ of $1 \% \mathrm{TC}$ was quickly added into the above boiling solutions with stirring for $8 \mathrm{~min}$, and then cooled down to room temperature to obtain the Au NPs (Wigginton and Vikesland, 2010). Method 2: $100 \mathrm{ml}$ of $0.01 \%$ tetrachloroauric acid trihydrate and $4 \mathrm{ml}$ of $1 \mathrm{mmol} / \mathrm{l}$ IP6 were mixed in a beaker and heated rapidly to boiling point. Subsequently, $1 \mathrm{ml}$ of $1 \%$ TC was added into the beaker with stirring for $10 \mathrm{~min}$, and then cooled down to room temperature to obtain the Au NPs (Wang et al., 2009). The obtained two different Au NPs were characterised by UV-visible spectroscopy and SEM.

\section{SERS measurement}

$400 \mu \mathrm{l} \mathrm{Au} \mathrm{NPs,} 30 \mu \mathrm{l}$ tested sample and $100 \mu \mathrm{l}$ electrolyte were added into $2 \mathrm{ml}$ quartz vial sequentially. After slight shaking for 5-10 s, the vial was put into sample cell to conduct SERS determination at exposure time of $10 \mathrm{~s}$ and laser power of $200 \mathrm{mw}$.

\section{Quantum chemical calculations}

Density functional theory (DFT) was performed with Gaussian 03W software (Shanghai eMolecular Technology Inc., Ltd (eMolTech), Shanghai, China) based on default spin of B3LYP and basis set of 6-31G $(+d)$ in order to optimise molecular structure and calculate theoretical vibration spectra. The result was exhibited by Gaussian view.

\section{Effects of electrolyte on SERS of patent blue $v$}

$\mathrm{NaCl}$ (1\%) and $\mathrm{MgSO}_{4}$ (1\%) aqueous solution were compared to study the impact of electrolyte on Raman signal of patent blue v. SERS measurement was the same as process 2.5 mentioned above.

\section{Semi-quantitative analysis of patent blue $v$ in drinks}

Every sample was measured for three times, and presented by mean values. The quantitative curve was established by Raman intensity correlated with the concentration of patent blue v. 


\section{Recoveries of three spiked samples}

To measure the recovery rate of the established method, standard solution of patent blue v was added into Gatorade sports drink, blended fruit drink and Rio cocktail in three concentrations, respectively. These samples were measured by SERS and the recovery rate was calculated according to the following formula: recovery rate $(\%)=(\mathrm{C}-\mathrm{A}) / \mathrm{B}$, where $\mathrm{C}=$ calculated concentration of patent blue $\mathrm{v}(\mathrm{mg} / \mathrm{kg}), \mathrm{A}=$ concentration of patent blue $v$ in blank samples $(0 \mathrm{mg} / \mathrm{kg})$, $\mathrm{B}=$ real concentration of patent blue $\mathrm{v}(\mathrm{mg} / \mathrm{kg})$.

\section{Results and discussion}

\section{Characterisation and comparison of two kinds of Au NPs}

UV-visible spectra and SEM image of Au NPs synthesised by method 1 and 2 were shown in Figure 1. The maximum absorption peak of Au NPs by method 1 was observed at $546 \mathrm{~nm}$ with broad peak width, whereas it was at 520 $\mathrm{nm}$ with a narrow peak width for Au NPs synthesised by method 2 (Figure 1).

As shown in Figure 2A, the diameter of Au NPs by method 1 was about 25-50 $\mathrm{nm}$ with serious aggregation. While Figure $2 \mathrm{~B}$ exhibited that Au NPs by method 2 was homogeneous and anti-aggregating (the size was about $25 \mathrm{~nm}$ ) (Haiss et al., 2007). The differences might be caused by the addition of $\mathrm{IP}_{6}$, which was a protective agent able to stabilise the size and improve the stability of Au NPs (Wang et al., 2009). UV-visible spectra and SEM image illustrated that Au NPs by method 2 had a better uniformity and anti-aggregation. Therefore, method 2 was used for synthesising Au NPs in the following experiment.

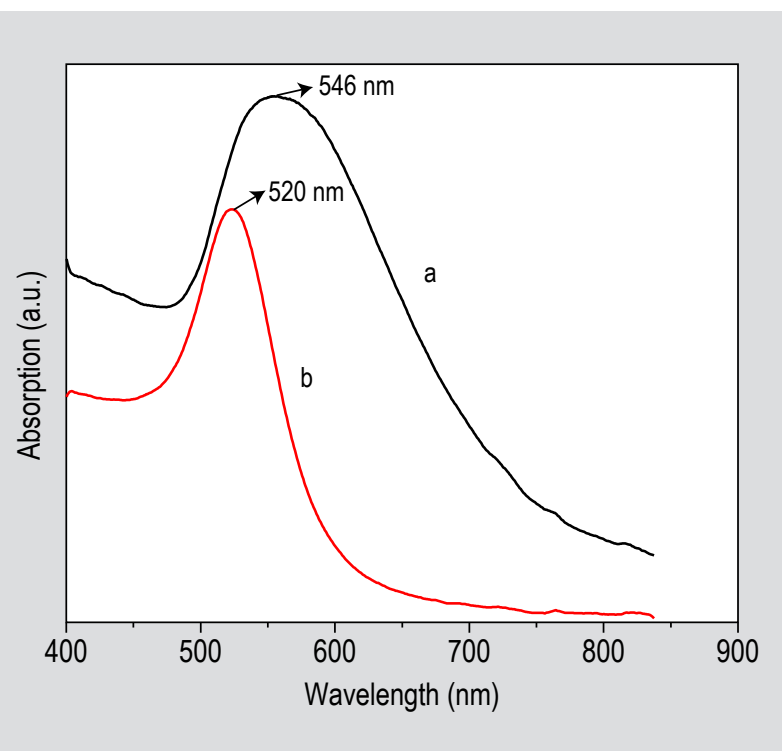

Figure 1. UV-Vis absorption spectra of Au nanoparticals obtained from method 1 (a) and 2 (b).
A

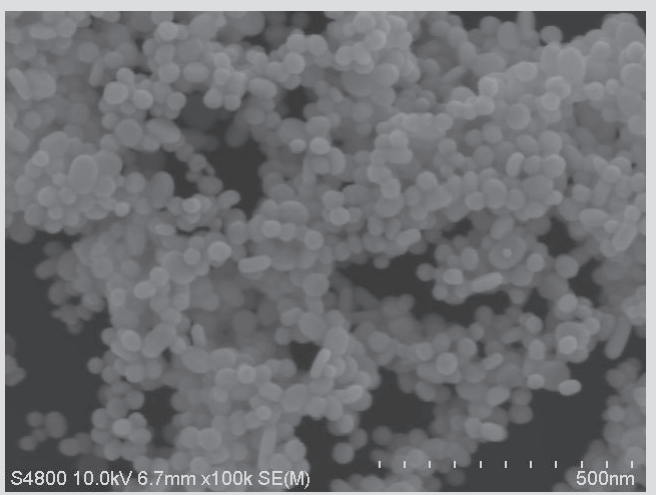

B

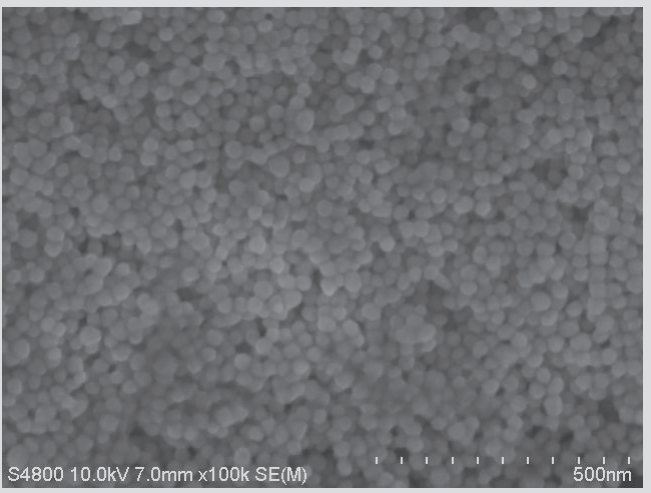

Figure 2. The SEM image of nanopaticles by method 1 (A) and method 2 (B).

\section{Analysis on theoretical and experimental Raman spectra of patent blue $v$}

The theoretical and experimental Raman spectra of patent blue $\mathrm{v}$ were presented in Figure 3. The major peaks and their assignments were presented in Table 1 . As can be seen in Figure 3, peaks at 572, 1,498 and 1,608 $\mathrm{cm}^{-1}$ were observed in both theoretical and experimental spectra, while peaks at $636,1,140$ and $1,210 \mathrm{~cm}^{-1}$ in theoretical (A) had no corresponding peaks with that in experimental spectrum (B). Furthermore, some slight deviations $(\leq 10$ $\mathrm{cm}^{-1}$ ) were observed between theoretical characteristic peaks and experimental ones. For example, theoretical characteristic peaks were at $394,430,774,850,900,920$, $948,1,166,1,190,1,274,1,346,1,432 \mathrm{~cm}^{-1}$ but experimental characteristic peaks were at $400,426,776,856,890,912$, $938,1,156,1,182,1,276,1,336,1,430 \mathrm{~cm}^{-1}$. The differences might be caused by the different conditions: the ideal DFT molecular vibration model had no matrix effect in theoretical spectrum, but in experimental spectrum, there were intermolecular interactions affected by multi-factors. Despite the existence of some deviations, the results were generally agreed that theoretical calculation was still consistent with experimental ones. 
Table 1. Theoretical and experimental Raman spectra of patent blue $v$ and its assignments. ${ }^{1}$

\begin{tabular}{|c|c|c|}
\hline Theoretical peaks $\left(\mathrm{cm}^{-1}\right)$ & Experimental peaks $\left(\mathrm{cm}^{-1}\right)$ & Assignments \\
\hline $394(w)$ & $400(w)$ & $\delta(\mathrm{C}-\mathrm{C})$ \\
\hline $430(m)$ & $426(m)$ & $\delta\left(\mathrm{CH}_{2}-\right) ; \delta$ (benzene ring) \\
\hline $572(w)$ & $572(w)$ & $\mathrm{U}(\mathrm{N}-\mathrm{H})$ \\
\hline $636(s)$ & - & $\delta$ (benzene ring) \\
\hline $774(w)$ & $776(w)$ & $\mathrm{u}(\mathrm{O}-\mathrm{H})$ \\
\hline 850 (s) & $856(w)$ & $\mathrm{u}(\mathrm{C}=\mathrm{C}) ; \mathrm{u}(\mathrm{C}-\mathrm{N})$ \\
\hline 900 (s) & 890 (s) & $\mathrm{u}(\mathrm{C}-\mathrm{N}-\mathrm{C})$ \\
\hline $920(w)$ & 912 (s) & U (-C-O-) \\
\hline $948(w)$ & 938 (s) & $\delta(\mathrm{O}-\mathrm{H})$ \\
\hline 1,140 (vs) & - & $\rho\left(-\mathrm{CH}_{3}\right) ; \mathrm{u}(\mathrm{C}-\mathrm{N})$ \\
\hline $1,166(s)$ & 1,156 (vs) & $\delta$ (benzene ring); $\mathrm{u}\left(-\mathrm{SO}_{2}\right)$ \\
\hline $1,190(s)$ & 1,182 (vs) & $\mathrm{u}\left(-\mathrm{SO}_{2}\right)$ \\
\hline- & $1,210(s)$ & $\delta(-\mathrm{C}-\mathrm{O}-)$ \\
\hline $1,274(s)$ & $1,276(s)$ & $\mathrm{U}(-\mathrm{C}-\mathrm{N}-)$ \\
\hline $1,346(s)$ & $1,336(\mathrm{~s})$ & $\delta\left(-\mathrm{CH}_{3}\right) ; \mathrm{u}(\mathrm{S}=\mathrm{O})$ \\
\hline $1,432(\mathrm{~m})$ & 1,430 (vs) & $\mathrm{U}(-\mathrm{C}-\mathrm{H}-)$ \\
\hline $1,492(w)$ & $1,492(m)$ & $\delta(\mathrm{N}-\mathrm{H})$ \\
\hline $1,608(m)$ & 1,608 (vs) & $\cup\left(-\mathrm{C}=\mathrm{N}^{+}-\right)$ \\
\hline
\end{tabular}

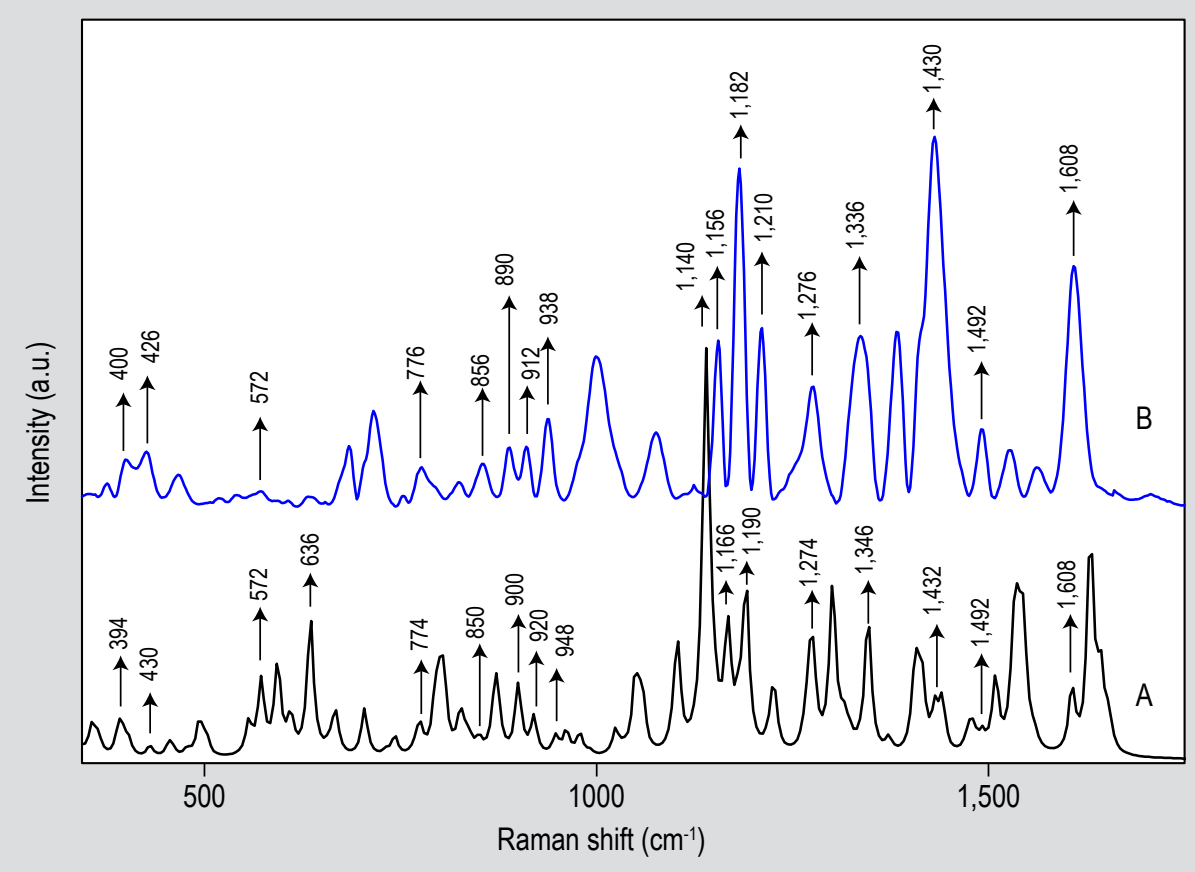

Figure 3. The theoretical (A) and experimental (B) Raman spectrum of patent blue $v$.

Table 1 showed that the prominent peaks of experimental Raman were observed at 1,156, 1,182, 1,210, 1,336, 1,430 and $1,608 \mathrm{~cm}^{-1}$, which were assigned to $\delta$ (benzene ring) $+\mathrm{v}\left(-\mathrm{SO}_{2}\right), \mathrm{v}\left(-\mathrm{SO}_{2}\right), \delta(-\mathrm{C}-\mathrm{O}-), \delta\left(-\mathrm{CH}_{3}\right)+\mathrm{v}(\mathrm{S}=\mathrm{O}), \mathrm{v}(-$
$\mathrm{C}-\mathrm{H}-)$ and $\mathrm{v}(-\mathrm{C}=\mathrm{N}+-)$. The major vibration modes related to $\mathrm{S}$ atom were at $1,156,1,182$ and $1,336 \mathrm{~cm}^{-1}$. The peaks at $572,856,890,1,276,1,492$ and $1,608 \mathrm{~cm}^{-1}$ were mainly affected by the vibration of $\mathrm{N}$ atom. Considering the better 
shape and stronger strength, $1,182 \mathrm{~cm}^{-1}$ was determined as the semi-quantitative characteristic peak.

\section{Semi-quantitative analysis of patent blue $\mathbf{v}$}

When comparing two electrolytes $\left(\mathrm{MgSO}_{4}\right.$ and $\left.\mathrm{NaCl}\right)$ used to enhance the Raman signal, $\mathrm{MgSO}_{4}$ was found to be better to enhance Raman effect of patent blue $v$ than that of $\mathrm{NaCl}$, this might be because $\mathrm{MgSO}_{4}$ could generate more SERS hot spots according to the Schulze-Hardy rule (Kamneva et al., 2015). SERS spectra of patent blue $\mathrm{v}$ in Gatorade sports drink, blended fruit drink and Rio cocktail were displayed in Figure 4A, 4B, 5A and the corresponding standard curves were respectively exhibited in Figure 5B. Spectral data of patent blue v in Gatorade sports drink was recorded from 100 to $4,278 \mathrm{~cm}^{-1}$. As shown in Figure 4A, Raman shifts in $1,130-1,200 \mathrm{~cm}^{-1}$ region were presented and characteristic peaks were analysed at 1,156 and $1,182 \mathrm{~cm}^{-1}$. It showed that the Raman intensity at 1,156 and $1,182 \mathrm{~cm}^{-1}$ increased along with the increase of the concentration of patent blue $\mathrm{v}$ in the range from 0 to $11.1 \mathrm{mg} / \mathrm{kg}$. As can be seen, the intensity at $1,182 \mathrm{~cm}^{-1}$ was a bit but not obviously different in the range among 0 to $0.997 \mathrm{mg} / \mathrm{kg}$. In this study, $0.997 \mathrm{mg} / \mathrm{kg}$ was regarded as the minimum detection limit of patent blue v in Gatorade sports drink. Figure 5B showed that the standard curve had a correlation coefficient of 0.99835 .

The second derivative spectrum has the advantages of high sensitivity of resolution and peak discrimination, and plays an important role in processing spectral data. Second-order derivative curves of patent blue $\mathrm{v}$ in blended fruit drink were shown in Figure 4B. The spectra rang of 1,160-1,206 $\mathrm{cm}^{-1}$ indicated that the peak at $1,182 \mathrm{~cm}^{-1}$ was proportional to the concentration of patent blue $\mathrm{v}$ (from 0 to $11.94 \mathrm{mg} / \mathrm{kg}$ ). As demonstrated in Figure 4B, the peak height of 0.99 $\mathrm{mg} / \mathrm{kg}$ was just noticeably different from $0 \mathrm{mg} / \mathrm{kg} .0 .99$ $\mathrm{mg} / \mathrm{kg}$ was thus regarded as the minimum detection limit. The corresponding standard curve of patent blue $\mathrm{v}$ had a correlation coefficient of 0.99139 as shown in Figure 5B.

Figure 5A presented the stack plots of patent blue $v$ in Rio cocktail. Obviously, the intensity of characteristic peaks was reduced with the decreasing concentration of patent blue v. In addition, it could be observed that peaks of 1,156 , $1,182,1,210 \mathrm{~cm}^{-1}$ were visible at the level of $0.53 \mathrm{mg} / \mathrm{kg}$, while peaks at 1,432 and $1,612 \mathrm{~cm}^{-1}$ were not detectable, and the peak of $1,182 \mathrm{~cm}^{-1}$ at the concentration of 0.53 $\mathrm{mg} / \mathrm{kg}$ was only a bit different from $0 \mathrm{mg} / \mathrm{kg}$. Therefore, $0.53 \mathrm{mg} / \mathrm{kg}$ was regarded as the minimum detection limit. The standard curve of patent blue $\mathrm{v}$ at $1,182 \mathrm{~cm}^{-1}$ exhibited a good linear relationship (Figure 5B).

\section{Recovery rate of patent blue $\mathrm{v}$ in three drinks}

Recovery rate was measured by adding three different concentrations of patent blue $\mathrm{v}$ into blank samples. Each sample was tested for three times of three parallel experiments. Mean values of recovery rate and statistical relative standard deviation (RSD) of each sample was represented in Table 2. It could be observed that the mean values of recovery rate in Gatorade sports drink, blended fruit drink and Rio cocktail were 98.16 104.55\%, 92.09 102.82\%, 94.36 99.17\% and the corresponding RSD were $3.05 \sim 4.15 \%, 4.65 \sim 5.00 \%, 1.77 \sim 7.75 \%$, respectively. The results indicated that the precision and recovery rate of the established method meet the analytical requirements.
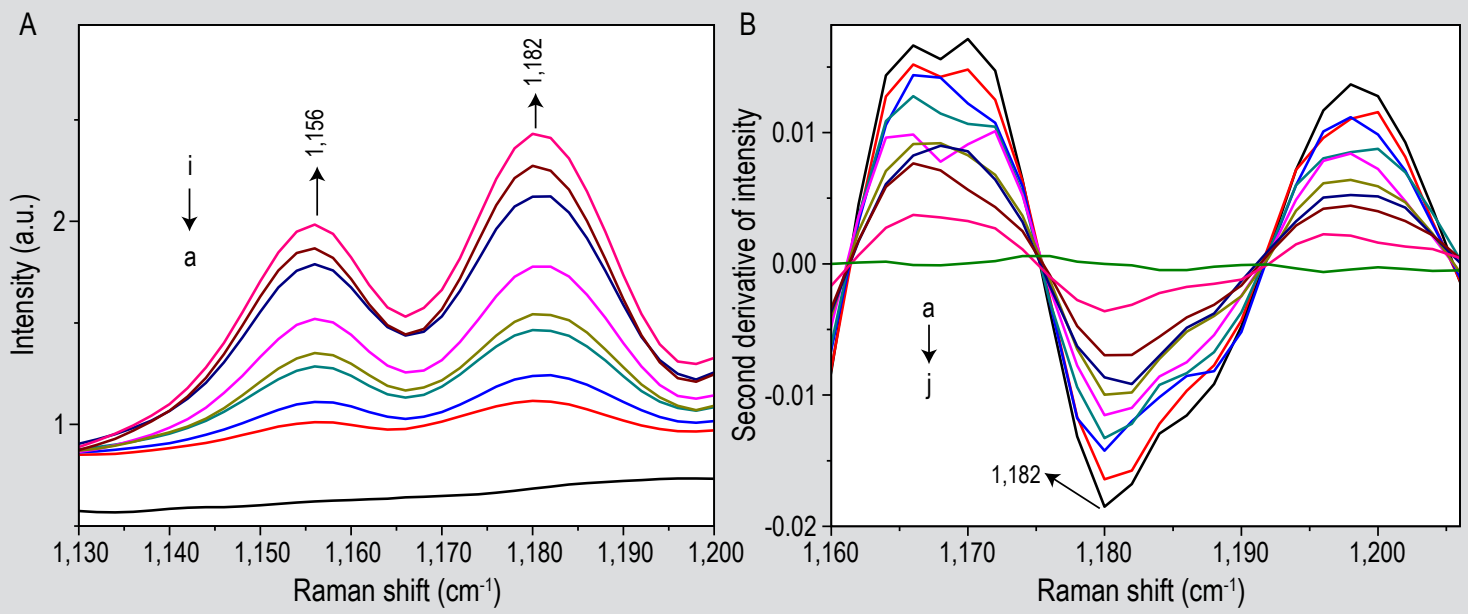

Figure 4. (A) Average three dimensional spectra $(n=3)$ of $E 131$ in Gatorade sports drink with spiked concentrations $(a \rightarrow i: 0,0.997$, $1.995,3,3.99,5.99,8.48,9.87,11.1 \mathrm{mg} / \mathrm{kg}$ ); (B) average second derivative spectra ( $\mathrm{n}=3$ ) of $\mathrm{E} 131$ in blended fruit drink with spiked concentration $(\mathrm{a} \rightarrow \mathrm{j}: 0,0.99,2.99,3.96,4.99,5.98,7.96,8.95,10.0,11.94 \mathrm{mg} / \mathrm{kg})$. 
A

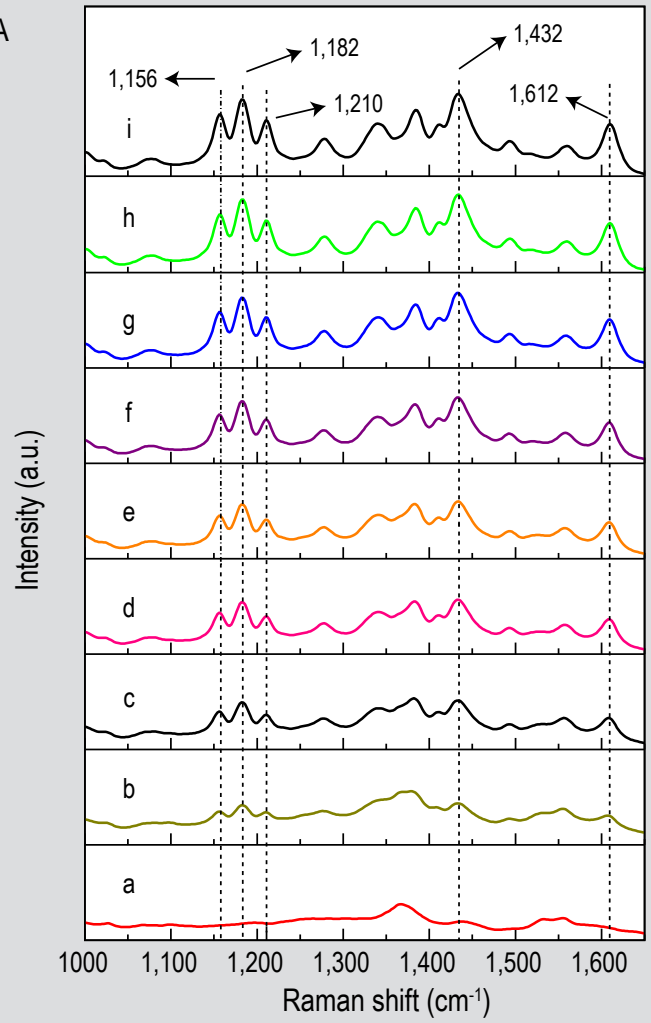

B 2.6
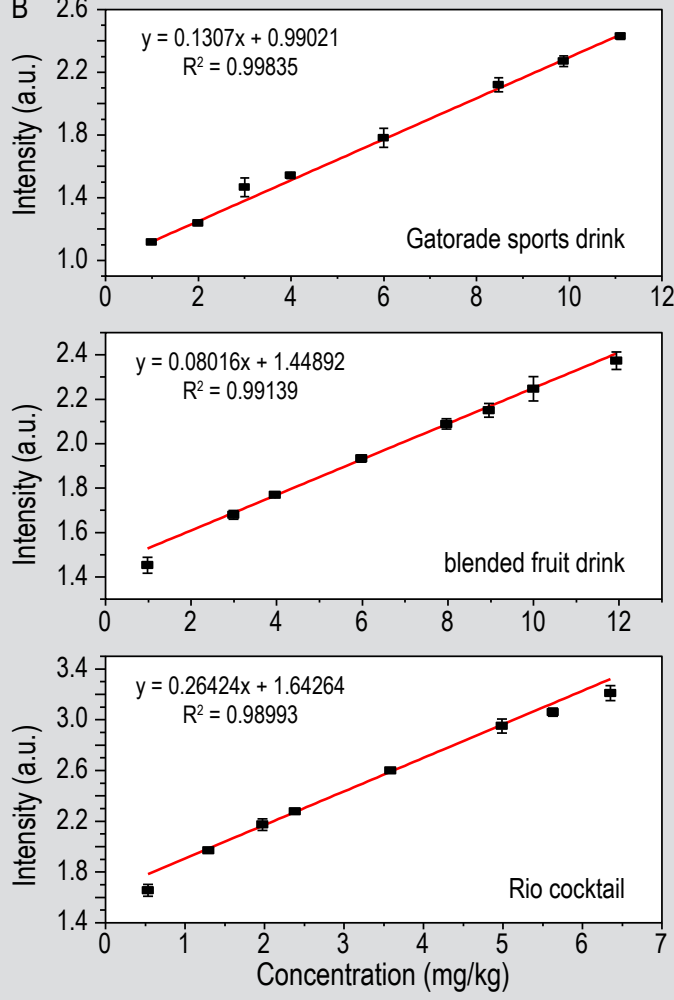

Figure 5. (A) Average spectra $(n=3)$ of patent blue $v$ in Rio cocktail with spiked gradient concentration $(\mathrm{a} \rightarrow \mathrm{i}: 0,0.53,1.30$, $1.97,2.39,3.58,4.99,5.63,6.35 \mathrm{mg} / \mathrm{kg}$ ); (B) standard curve of patent blue $v$ in Gatorade sports drink, blended fruit drink and Rio cocktail.
Table 2. Precision and recovery rate of patent blue $v$ in three drinks.

\begin{tabular}{|c|c|c|c|}
\hline $\begin{array}{l}\text { Food type } \\
\text { Spiked value } \\
\text { (mg/kg) }\end{array}$ & $\begin{array}{l}\text { Detected value } \\
\text { (mg/kg) }\end{array}$ & $\begin{array}{l}\text { Mean recovery } \\
\text { rate }(\%)\end{array}$ & $\begin{array}{l}\text { RSD } \\
(\%)\end{array}$ \\
\hline \multicolumn{4}{|c|}{ Gatorade sports drink } \\
\hline 10 & $\begin{array}{r}9.4828 \\
10.0641 \\
9.9006\end{array}$ & 98.16 & 3.05 \\
\hline 7.5 & $\begin{array}{l}7.7789 \\
7.6030 \\
8.1420\end{array}$ & 104.55 & 3.51 \\
\hline 3.5 & $\begin{array}{l}3.3430 \\
3.5299 \\
3.6295\end{array}$ & 100.02 & 4.15 \\
\hline Blended fruit drink & & & \\
\hline 10 & $\begin{array}{r}9.7392 \\
10.6870 \\
10.4204\end{array}$ & 102.82 & 4.7 \\
\hline 7 & $\begin{array}{l}6.4544 \\
6.1504 \\
6.7970\end{array}$ & 92.39 & 5.0 \\
\hline 3.5 & $\begin{array}{l}3.4845 \\
3.1750 \\
3.3251\end{array}$ & 95.09 & 4.65 \\
\hline Rio cocktail & & & \\
\hline 5.2 & $\begin{array}{l}5.4114 \\
5.2270 \\
5.3542\end{array}$ & 94.36 & 1.77 \\
\hline 3.12 & $\begin{array}{l}2.7822 \\
3.0256 \\
3.2499\end{array}$ & 96.77 & 7.75 \\
\hline 1.28 & $\begin{array}{l}1.2709 \\
1.1772 \\
1.3600\end{array}$ & 99.17 & 7.20 \\
\hline
\end{tabular}

\section{Conclusion}

The present study established a SERS based semiquantitative detection method for patent blue $\mathrm{v}$ in three beverages: Gatorade sports drink, blended fruit drink and Rio cocktail. The method was based on Au NPs and magnesium sulphate electrolyte and accessed by the strong peak at $1,180 / 1,182 \mathrm{~cm}^{-1}$. The results showed that the method had high reproducibility and accuracy. The sensitivity of patent blue $\mathrm{v}$ was high and the minimum detection limits were as low as $0.997,0.99$ and $0.53 \mathrm{mg} / \mathrm{kg}$ in the drinks (Gatorade sports drink, blended fruit drink and Rio cocktail). The test time of each sample can be as short as $8 \mathrm{~min}$. In conclusion, because of the simplicity of SERS method, it has a promising application prospect to monitor patent blue $\mathrm{v}$ in real samples, such as different drinks. 


\section{Acknowledgements}

The authors want to thank the Food and Drug Administration Jiangxi Province (Nanchang, China) for their kindly assistance in obtaining samples.

This work was supported by Science and Technology Support Project of Jiangxi Province (NO. 20151BBG70066), Jiangxi Provincial Academic and Technical Leaders Program (20182BCB22003), Modern Agricultural Research Collaborative Innovation Special Funds of Jiangxi Province (NO. JXXTCX201703-3).

\section{Conflict of interest}

All the authors declare there is no conflict of interest.

\section{Ethical approval}

This paper does not contain any studies with human participants or animals performed by any of the authors.

\section{References}

Ai, Y.J., Liang, P., Wu, Y.X., Dong, Q.M., Li, J.B., Bai, Y., Xu, B.J., Yu, Z. and Ni, D.J., 2018. Rapid qualitative and quantitative determination of food colorants by both Raman spectra and Surface-enhanced Raman Scattering (SERS). Food Chemistry 241: 427-433.

Aoki, P.H.B., Furini, L.N., Alessi, P., Aliaga, A.E. and Constantino, C.J.L., 2013. Surface-enhanced Raman scattering (SERS) applied to cancer diagnosis and detection of pesticides, explosives, and drugs. Reviews in Analytical Chemistry 32: 55-76.

Benedetti, D.P., Zhang, J., Tague, T.J., Lombardi, J.R. and Leona, M., 2014. In situ microanalysis of organic colorants by inkjet colloid deposition surface-enhanced Raman scattering. Journal of Raman Spectroscopy 45: 123-127.

Cai, L.M., Deng, Z., Dong, J., Song, S.D., Wang, Y.R. and Chen, X., 2017. Fabrication of non-woven fabric-based SERS substrate for direct detection of pesticide residues in fruits. Journal of Analysis and Testing 1: 322-329.

Chen, Q.S., Yang, M.X., Yang, X.J., Li, H.H., Guo, Z.M. and Rahma, M.H., 2018. A large Raman scattering cross-section molecular embedded SERS aptasensor for ultrasensitive aflatoxin B1 detection using CS-Fe3O4 for signal enrichment. Spectrochimica Acta part A - Molecular and Biomolecular Spectroscopy 189: 147-153.

European Food Safety Authority (EFSA), 2013. Scientific opinion on the re-evaluation of patent blue $\mathrm{V}$ (E 131) as a food additive. EFSA Journal 11(3): 2818.

Gao, Y.Q., Wang, M.L, Yang, X.B. and Zhao, J.W., 2014. Rapid detection of quinoline yellow in soft drinks using polypyrrole/single-walled carbon nanotubes composites modified glass carbon electrode. Journal of Electroanalytical Chemistry 735: 84-89.
Genualdi, S., MacMahon, S., Robbins, K., Farris, S., Shyong, N. and DeJager, L., 2016. Method development and survey of Sudan I-IV in palm oil and chilli spices in the Washington, DC, area. Food Additives and Contaminants part A - Chemistry Analysis Control Exposure \& Risk Assessment 33: 583-591.

Gukowsky, J.C., Xie, T.Y., Gao, S.Y., Qu, Y.Q. and He, L.L., 2018. Rapid identification of artificial and natural food colorants with surface enhanced Raman spectroscopy. Food Control 92: 267-275.

Haiss, W., Thanh, N.T.K., Aveyard, J. and Fernig, D.G., 2007. Determination of size and concentration of gold nanoparticles from UV-vis spectra. Analytical Chemistry 79: 4215-4221.

Han, C.Q., Yao, Y., Wang, W., Qu, L.L., Bradley, L., Sun, S.L. and Zhao, Y.P., 2017. Rapid and sensitive detection of sodium saccharin in soft drinks by silver nanorod array SERS substrates. Sensors and Actuators B: Chemical 251: 272-279.

Haruka, Y., 1987. Charge-transfer band and SERS mechanism for the pyridine-Ag system. Surface Science 182: 269-286.

Kamneva, N.N., Ōsawa, E., Marynin, A.I., Goga, S.T., Tkachenko, V.V. and Kryshtal, A.P., 2015. Colloidal solution of $3 \mathrm{~nm}$ Bucky diamond: primary particles of detonation nanodiamond. Physics of Liquid Matter: Modern Problems 171: 199-217.

Lee, W.M.Y., McCoy, C.P., Donnelly, R.F. and Bell, S.E.J., 2016. Swellable polymer films containing Au nanoparticles for point-ofcare therapeutic drug monitoring using surface-enhanced Raman spectroscopy. Analytica Chimica Acta 912: 111-116.

Li, J.F., Tian, X.D., Li, S.B., Anema, J.R., Yang, Z.L., Ding, Y., Wu, Y.F., Zeng, Y.M., Chen, Q.Z., Ren, B., Wang, Z.Q. and Tian Z.Q., 2013. Surface analysis using shell-isolated nanoparticle-enhanced Raman spectroscopy. Nature Protocols 8: 52-65.

Lofstedt, R., 2011. Communicating food risks in an era of growing public distrust: three case studies. Risk Analysis 33: 192-202.

Ma, P.Y., Liang, F.H., Li, X.P., Yang, Q.Q., Wang, D., Song, D.Q., Gao, D.J. and Wang, X.H., 2014. Development and optimization of a SERS method for on-site determination of nitrite in foods and water. Food Analytical Methods 7: 1866-1873.

Meng, J., Qin, S., Zhang, L. and Yang, L.B., 2016. Designing of a novel gold nanodumbbells SERS substrate for detection of prohibited colorants in drinks. Applied Surface Science 366: 181-186.

Oplatowska, M., Stevenson, P.J., Schulz, C. and Elliott, C., 2011. Development of a simple gel permeation clean-up procedure coupled to a rapid disequilibrium enzyme-linked immunosorbent assay (ELISA) for the detection of Sudan I dye in spices and sauces. Analytical and Bioanalytical Chemistry 401: 1411-1422.

Pearson, B., Mills, A., Tucker, M., Gao, S., McLandsborough, L. and He, L.L., 2018. Rationalizing and advancing the 3-MPBA SERS sandwich assay for rapid detection of bacteria in environmental and food matrices. Food Microbiology 72: 89-97.

Peksa, V., Jahn, M., Štolcová, L., Schulz, V., Proška, J., Procházka, M., Weber, K., Cialla-May, D. and Popp, J., 2015. Quantitative SERS analysis of azorubine(E 122) in sweet drinks. Analytical Chemistry 87: 2840-2844.

Sharma, H.S.S., Carmichael, E. and McCall, D., 2016. Fabrication of SERS substrate for the detection of rhodamine 6G, glyphosate, melamine and salicylic acid. Vibrational Spectroscopy 83: 159-169. 
Siddhanta, S., Wróbel, M.S. and Barman, I., 2016. Integration of protein tethering in a rapid and label-free SERS screening platform for drugs of abuse. Chemical Communications 52: 9016-9019.

Sur, U.K., 2017. Surface-enhanced Raman scattering. Intech Open, London, UK.

Wang, H., Guo, X.Y., Fu, S.Y., Yang, T.X., Wen, Y. and Yang, H.F., 2015. Optimized core-shell Au@Ag nanoparticles for label-free Raman determination of trace Rhodamine B with cancer risk in food product. Food Chemistry 188: 137-142.

Wang, L., Xu, X.M., Chen, Y.S., Ren, J. and Liu, Y.T., 2018. HPTLC-FLDSERS as a facile and reliable screening tool: exemplarily shown with tyramine in cheese. Journal of Food and Drug Analysis 26: 688-695.

Wang, N., Yang, H.F., Zhu, X., Zhang, R., Wang, Y., Huang, G.F. and Zhang, Z.R., 2009. Synthesis of anti-aggregation silver nanoparticles based on inositol hexakisphosphoric micelles for a stable surface enhanced Raman scattering substrate. Nanotechnology 20: 315603315608.

Wigginton, K.R. and Vikesland, P.J., 2010. Gold-coated polycarbonate membrane filter for pathogen concentration and SERS-based detection. Analyst 135: 1320-1326.
Xian, R.Q., Wang, X.B., Li, Q.Y., Shi, F. and Li, J.J., 2013. Simultaneous determination of 10 synthetic colors in drink by solid-phase extraction coupled with HPLC/photodiode array detection. Modern Food Science and Technology 29: 1413-1416.

Xie, Y.F., Chen, T., Guo, Y.H., Cheng, Y.L., Qian, H. and Yao, W.R., 2019. Rapid SERS detection of acid orange II and brilliant blue in food by using Fe3O4@Au core-shell substrate. Food Chemistry 270: 173-180.

Xie, Y.F., Li, Y., Niu, L. and Yao, W.R., 2012. A novel surface-enhanced Raman scattering sensor to detect prohibited colorants in food by graphene/silver nanocomposite. Talanta 100: 32-37.

Xu, M.L., Gao, Y., Han, X.X. and Zhao, B., 2017. Detection of pesticide residues in food using surface-enhanced Raman spectroscopy: a review. Journal of Agricultural and Food Chemistry 65: 6719-6726.

Zhou, Y., Chen, J., Zhang, L. and Yang, L.B., 2012. Multifunctional $\mathrm{TiO}_{2}$-coated Ag nanowire arrays as recyclable SERS substrates for the detection of organic pollutants. European Journal of Inorganic Chemistry 2012(19): 3176-3182.

Zhu, J., Liu, M., Li, J.J., Li, X. and Zhao, J.W., 2018. Multi-branched gold nanostars with fractal structure for SERS detection of the pesticide thiram. Spectrochimica Acta part A: Molecular and Biomolecular Spectroscopy 189: 586-593. 